\title{
Pattern of Salivary Gland Tumour in Sokoto, North-Western Nigeria
}

\author{
Daniel Aliyu', Kufre Robert Iseh1, Saddiku Mallami Sahabi², Stanley Baba Amutta1, \\ Mohammed Abdullahi', Mfon Ime Inoh'1 \\ ${ }^{1}$ Department of Ear, Nose and Throat, Usmanu Danfodiyo University Teaching Hospital, Sokoto, Nigeria \\ ${ }^{2}$ Department of Histopathology, Usmanu Danfodiyo University Teaching Hospital, Sokoto, Nigeria \\ Email: danoaliyu@yahoo.com
}

Received 13 February 2016; accepted 27 May 2016; published 30 May 2016

Copyright (C) 2016 by authors and Scientific Research Publishing Inc.

This work is licensed under the Creative Commons Attribution International License (CC BY).

http://creativecommons.org/licenses/by/4.0/

(c) (7) Open Access

\begin{abstract}
Background: Salivary gland tumours though rare but constitute a heterogeneous group of tumours accounting for $5 \%$ of head and neck tumours with a high incidence reported in other part of the world compared with studies in Sub-saharan Africa. Aim: To describe the dermographic and histopathological patterns of salivary gland tumuors in a tertiary health institution Sokoto. Materials and Method: This was a five-year descriptive and retrospective analysis of all patients diagnosed and managed with salivary gland tumour in the department of ear, nose and throat, Usmanu Danfodiyo University Teaching Hospital Sokoto between January 2010 and December 2014. Clinical records and histopathological slides of these patients were retrieved and data extracted from the case files included patients demography, site of the tumour, and histopathological diagnosis. Data obtained were analysed using IBM-SPSS version 22. Results: A total of 103 salivary gland tumours (SGTs) during the study period. Age ranged from 1 year to 75 years with a mean age of 41.66 $( \pm 17.80)$ years. There was a male preponderance of $53.4 \%$ and $46.6 \%$ female with a M:F of $1.2: 1$. Histologically, $35(34.0 \%)$ were benign and $68(66.0 \%)$ were malignant lesion. Minor salivary gland $63(61.2 \%)$ was the commonest gland involved followed by the parotid $27(26.2 \%)$ gland. Squamous cell carcinoma (SCC) was most frequent malignant lesion and pleomorphic adenoma was the commonest benign tumour. Conclusion: Minor salivary glands of the palate are the principal site for salivary gland malignancy with male preponderance and SCC being the most frequent malignant lesion. Therefore any SGTs should raise a high index of suspicion.
\end{abstract}

\section{Keywords}

Salivary Gland, Tumour, Malignant, Benign

\section{Introduction}

Salivary glands though useful to the body, may give rise to many disease conditions including tumours. They are

How to cite this paper: Aliyu, D., Iseh, K.R., Sahabi, S.M., Amutta, S.B., Abdullahi, M. and Inoh, M.I. (2016) Pattern of Salivary Gland Tumour in Sokoto, North-Western Nigeria. International Journal of Clinical Medicine, 7, 347-352.

http://dx.doi.org/10.4236/ijcm.2016.75037 
generally classified as major or minor [1]. Salivary glands tumours (SGTs) constitute a heterogeneous group of tumours [2] accounting for less than $2 \%$ of all human tumours [3] and between $2.8 \%-10.0 \%$ of all head and neck tumours [4]. According to the World Health Organization (WHO), global incidence of salivary gland tumors is about 0.4 - 13.5 cases per 100,000-population annually [5]. These tumors occur mainly in the parotid, submandibular, and minor salivary glands; while the sublingual gland is rarely affected [6]. Most studies in Africa have noted benign tumours especially the pleomorphic adenoma as more common than the malignant ones, particularly the muco-epidermoid and acinic cell carcinoma [7]-[9]. The parotid tends to have predilection for benign tumours while the sublingual and other minor salivary glands have higher predilection for malignant tumours [8] [10]. Because of their varied histologic characters and wide range of biologic behavior, salivary gland tumours are challenging to both surgeons and histopathologists. Even microscopically, these tumours resemble. Some like pleomorphic adenoma are characterized by recurrence and repeated surgical failures. Global epidemiological differences in the distribution of salivary gland tumors have been noted [9]. There is dearth of information in medical literature on the pattern of salivary gland tumour in our region and the aim of this study was to retrospectically profile the histopatological pattern of major and minor salivary gland tumour regarding age, gender, tumour size amongst Nigerian patients. Advocating the need for a detailed SGTs registry in all hospital.

\section{Materials and Methods}

The study is a five-year retrospective study of all patients diagnosed and managed with salivary gland tumour in the department of Ear, Nose and Throat, Usmanu Danfodiyo University Teaching Hospital, Sokoto, Sokoto State, North-western Nigeria, between January 2010 and December 2014. Histopathologically diagnosed salivary gland tumours of consecutive patients were retrieved from the hospital records. All slides were reevaluated for histopathological diagnosis, and when in doubt, tissue blocks were retrieved for section cutting and stained with hematoxylin and eosin stain for re-examination and diagnosis. Excluded from the study were patients whose case files could not be located, and those with incomplete clinical information in their case files. Information retrieved from patients' case files included-patient's demographics, anatomical location of the tumor, and histopathologic diagnosis. These SGTs were classified in accordance with the 2005 World Health Organization (WHO) Histological Classification of Salivary Gland Tumours [5], and the information obtained was fed into a spreadsheet and the data generated was analysed using IBM. SPSS version 22. The results obtained were presented in tabular forms and charts following a descriptive analysis.

\section{Results}

A total of 103 SGTs were seen within the study period. Benign lesions were 35 (34.0\%) while malignant 68 (66.0\%) were malignant. Table 1 is a summary of the demographic distribution of SGTs. Generally, there was a male preponderance of $53.4 \%$ and $46.6 \%$ female, with a male to female ratio of $1.2: 1$. The age range of the patients with SGTs was 1 - 75 years, with a mean age of $41.66( \pm 17.80)$ years, and peaks at the $4^{\text {th }}$ decade of life.

Table 2 shows the various histologic types of SGTs seen within the study period. Squamous cell carcinoma (SCC) was most frequent with 32 cases representing $31.1 \%$ of all the SGTs and $47.1 \%$ of malignant SGTs. The mean age for malignant tumours was $46.41( \pm 16.31)$ years while for benign tumours $32.43( \pm 17.12)$ years. There was a statistically significant difference in the mean ages of the malignant and benign SGTs $(p=0.05)$. Benign SGTs occurred more in the females than males with a male: female ratio of 1:1.2, while malignant SGTs occurred more in the males than females with male: female ratio of 1.4:1.

In terms of anatomical site of SGTs, the minor salivary gland with $63(61.2 \%)$ cases was the commonest site of occurrence, followed by the parotid with 27 (26.2\%) cases, then the submandibular 9 (8.7\%) and the sublingual 4 (3.9\%). Among the minor salivary glands, the palate with 23 (22.3\%) cases was the commonest, while the floor of the mouth had the least occurrence of SGTs. Table 2 shows the site distribution of the SGTs.

\section{Discussion}

This study reviewed 103 cases of SGTs within a five-year period, with patients' ages ranging between the $1^{\text {st }}$ to $7^{\text {th }}$ decades of life with a peak at the $4^{\text {th }}$ decade, similar to other African studies [6] [11]. Over 70\% of the patients under review were between 21 - 60 years. This is different from studies in the western world which noted a peak age of SGTs in the $7^{\text {th }}$ and $8^{\text {th }}$ decades, [12] implying a relatively more elderly patients with these 
Table 1. Demographic overview of the SGTs.

\begin{tabular}{|c|c|c|c|c|c|c|}
\hline SGTs & Freq. & M: F & $\begin{array}{l}\text { Age range } \\
\text { (yrs) }\end{array}$ & $\begin{array}{l}\text { Mean age (yrs) } \\
( \pm \mathrm{SD})\end{array}$ & $\begin{array}{l}\text { Percentage of total } \\
\text { tumours }\end{array}$ & $\begin{array}{l}\text { Percentage in group (benign } \\
\text { or malignant) }\end{array}$ \\
\hline \multicolumn{7}{|c|}{ BENIGN } \\
\hline Pleomorphic adenoma & 27 & $1.1: 1$ & $15-75$ & $36.30( \pm 16.84\}$ & 26.2 & 77.1 \\
\hline Haemangioma & 3 & $2: 1$ & $13-25$ & $17.00( \pm 6.93)$ & 2.9 & 8.6 \\
\hline Monomorphic adenoma & 2 & $0: 2$ & $25-38$ & $30.50( \pm 10.61)$ & 1.9 & 5.7 \\
\hline Neurofibroma & 2 & $0: 2$ & $20-22$ & $21.00( \pm 1.41)$ & 1.9 & 5.7 \\
\hline Lymphangioma & 1 & $0: 1$ & 1 & 0.90 & 1.0 & 2.9 \\
\hline Total benign & 35 & $1: 1.2$ & $1-75$ & $32.43( \pm 17.12)$ & 34.0 & 100 \\
\hline \multicolumn{7}{|c|}{ MALIGNANT } \\
\hline Squamous cell carcinoma & 32 & $1.3: 1$ & $20-71$ & $49.38( \pm 16.01)$ & 31.1 & 47.1 \\
\hline Adenoid cystic carcinoma & 16 & 1.3:1 & $23-75$ & $49.19( \pm 15.68)$ & 15.5 & 23.5 \\
\hline Mucoepidermoid carcinoma & 6 & $1: 1$ & $13-53$ & $30.83( \pm 16.73)$ & 5.8 & 8.8 \\
\hline Sarcoma & 5 & $1.5: 1$ & $25-45$ & $33.20( \pm 8.87)$ & 4.9 & 7.4 \\
\hline Lymphoma & 3 & $2: 1$ & $35-58$ & $47.67( \pm 11.68)$ & 2.9 & 4.4 \\
\hline $\begin{array}{l}\text { Carcinoma ex-pleomorphic } \\
\text { adenoma }\end{array}$ & 2 & $2: 0$ & $55-60$ & $57.50( \pm 3.54)$ & 1.9 & 2.9 \\
\hline Acinic cell carcinoma & 1 & $0: 1$ & 51 & 51.00 & 1.0 & 1.5 \\
\hline Adenocarcinoma & 1 & $0: 1$ & 24 & 24.00 & 1.0 & 1.5 \\
\hline Salivary ductal carcinoma & 1 & $1: 0$ & 35 & 35.00 & 1.0 & 1.5 \\
\hline Basal cell adenocarcinoma & 1 & $1: 0$ & 70 & 70.00 & 1.0 & 1.5 \\
\hline Total malignant & 68 & $1.4: 1$ & $13-75$ & $46.41( \pm 16.31)$ & 66.0 & 100 \\
\hline TOTAL & 103 & $1.2: 1$ & $1-75$ & $41.66( \pm 17.80)$ & 100.0 & \\
\hline
\end{tabular}

tumours. Yaor [13] noted that SGT patients are usually younger at presentation in Africa. Poverty, illiteracy, religious faith and low life expectancy may be proffered as some of the reason for the fewer number of elderly SGT patients seen in African studies.

Unlike other studies that have reported female preponderance in SGTs [6] [9], our finding was that of male dominance and is similar to the findings of Silas et al [14] in North-Central Nigeria, who attributed this to cultural practices which refuses females from attending hospitals alone without permission from their husbands. In addition however, most women in northern Nigeria are not gainfully employed, and this causes serious problem to the family when it comes to payment of hospital bills. However, there was no significant association between the gender of our patients and the histological type of SGT.

With regards to tumour type, there were more malignant than benign tumours seen in this study, representing 68 (66.0\%) of all the SGTs. However, many studies have reported benign SGTs as being commoner with differing values of $78.3 \%$ [3], 59.7\% [10], 63.0\% [14], 55.7\% [15], and 71.4\% [16]. These may be attributed to the differences in methodologies employed in the different studies. However, Lawal et al [17] in Ibadan and Kalburge et al. [18] had result similar to our finding, with malignant SGTs predominating. Our health facility is a tertiary center, with referrals from Birnin-Kebbi, Gusau, Katsina and other neighboring cities. The cost of specialized medical treatment in our facility when compared with other tertiary health facilities in Nigeria was by far the cheapest during the period under review. These reasons may account for the higher incidence of malignant SGTs in this study, as the cost of management of these patients are usually more expensive requiring even post-operative radiotherapy with rehabilitation, and patients will naturally present in facilities where the cost of management will be affordable.

Many studies across the globe have described the parotid gland as the commonest site of SGTs [9] [15] [16] [19] [20]. But in our study, the minor salivary glands with 63 (61.2\%) cases, was the commonest site of the SGTs that is similar to findings in other studies [6] [21]. A possibility of racial variations existing in the clinico-pathologic distribution of SGTs, with Africans having less proportion of SGTs in the parotid gland, but more proportion occurring in the minor salivary and submandibular glands when compared with white populations in 
Table 2. Histopathological diagnosis and site distribution of SGTs $(n=103)$.

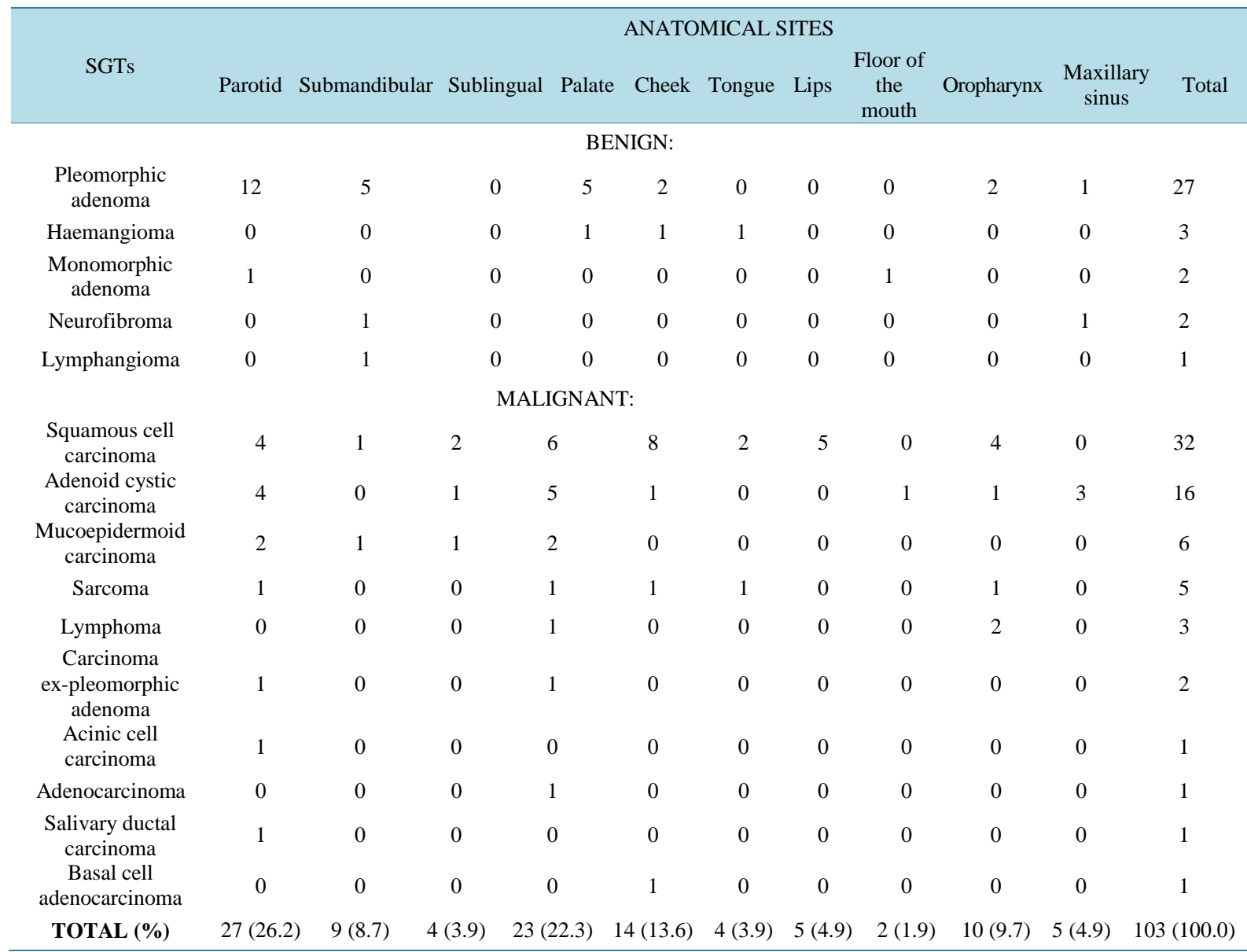

Europe and America, as been proposed [22]. This possibility is further enhanced by our findings with the parotid having 27 (26.2\%) cases and the submandibular 9 (8.7\%). The sublingual gland had 4 (3.9\%) cases, and this supports various reports about the rarity of SGTs in the sublingual gland [9]. Traditionally, the distribution of salivary neoplasms between sites has followed a rule of 1:0.1:0.1:0.01 ratio for parotid, submandibular, minor salivary glands and sublingual tumours, respectively. Oti et al. [23] in Ghana, found a ratio of 3:2:1:0, while the site distribution ratio from our study was 3:1:7:0.44. With regards to the individual site distribution of the minor salivary gland tumours, palate was the most affected 23 (22.3\%), while the floor of the mouth was the least affected 2 (1.9\%) and is consistent with findings from previous studies in both Western and African continent [7] [9] [24].

With respect to frequency of the individual histological types of SGTs, squamous cell carcinoma was the most common in our study, accounting for $31.1 \%$ of all the SGTs and $47.1 \%$ of the malignant SGTs. This was followed by 27 cases of pleomorphic adenoma comprising $26.2 \%$ of the total tumours and $77.1 \%$ of benign SGTs in the study. Adenoid cystic carcinoma was the third most common SGT in our study, comprising $15.5 \%$ of the SGTs and $23.5 \%$ of the malignant, while mucoepidermoid carcinoma was next and comprised $5.8 \%$ of the SGTs and $8.8 \%$ of the malignant. This is still in support with the general global high incidence of pleomorphic adenoma [5]. However, other indigenous studies have reported mucoepidermoid carcinoma [9] and adenoid cystic carcinoma [16] as the most common malignant SGTs and not squamous cell carcinoma as found in our study. All the sublingual SGTs in this study were malignant. The minor salivary glands were most associated with malignancy and this is similar to other reports [3] [7], with the palate being the commonest individual site involved. The ratio of malignant to benign tumours for submandibular SGTs was 1:3.5; while for parotid SGTs was 1.1:1. Contrary to western reports that the submandibular SGTs had more malignant tendency, our study revealed a more benign tendency of the submandibular SGTs. However, our findings further reiterate the assertion that pa- 
rotid SGTs are more likely to be malignant in African populations [6] [7].

The mean age for malignant SGTs in our study was $46.41( \pm 16.31)$ years, while for benign SGTs 32.43 $( \pm 17.12)$ years. The benign SGTs occurred approximately 10 years earlier than the malignant ones, and this resonates findings from other studies [5].

\section{Conclusion}

It can be concluded from this study that the most common SGTs is squamous cell carcinoma, with the minor salivary glands recording the highest malignancy. The parotid gland in this study had slightly elevated malignant than benign tumours. Results from this study agree with findings from other African studies. The need for a detailed SGT registry in all hospitals in order to enhance a broader data collection that will facilitate study of SGTs variations is advocated.

\section{References}

[1] Sarfraz, T., Qureshi, S.M., Khan, S.S., Janjua, O.S., Alamgir, W. and Muhamma (2011) Clinicopathological Aspects of Malignant Salivary Gland Neoplasms-A Study of 150 Cases at AFIP, Rawalpindi (Pakistan). Pakistan Armed Forces Medical Journal, 61, 194-197.

[2] Bell, D. and Hanna, E.Y. (2012) Salivary Gland Cancers: Biology and Molecular Targets for Therapy. Current Oncology Reports, 14, 166-174. http://dx.doi.org/10.1007/s11912-012-0220-5

[3] Oliveira, F.A., Duarte, E.C., Taveira, C.T., Máximo, A.A, de Aquino, E.C., Alencar, R.C. and Vencio, E.F. (2009) Salivary Gland Tumor: A Review of 599 Cases in a Brazilian Population. Head and Neck Pathology, 3, 271-275. http://dx.doi.org/10.1007/s12105-009-0139-9

[4] Odukoya, O. (1990) Pleomorphic Adenoma of Salivary Glands in Lagos, Nigeria. African Journal of Medicine and Sciences, 19, 195-199.

[5] Barnes, L., Eveson, J., Reichart, P. and Sidransky, D. (2005) Tumors of the Salivary Glands. World Health Organization Classification of Tumors. Pathology and Genetics of Head and Neck Tumors. IARC, Lyon, 210-281.

[6] Bahra, J., Butt, F., Dimba, E. and Macigo, F. (2012) Patterns of Salivary Tumours at a University Teaching Hospital in Kenya. OJST, 2, 280-285. http://dx.doi.org/10.4236/ojst.2012.24049

[7] Vuhahula, E.A.M. (2004) Salivary Gland Tumors in Uganda: Clinical Pathological Study. African Health Sciences, 4, $15-23$.

[8] Al-Khateeb, T.H. and Ababneh, K.T. (2007) Salivary Tumors in North Jordanians: A Descriptive Study. Oral Surgery, Oral Medicine, Oral Pathology, Oral Radiology \& Endodontics, 103, 53-59. http://dx.doi.org/10.1016/j.tripleo.2006.11.017

[9] Ochicha, O., Malami, S., Mohammed, A. and Atanda, A. (2009) A Histopathologic Study of Salivary Gland Tumors in Kano, Northern Nigeria. Indian Journal of Pathology \& Microbiology, 52, 473-476. http://dx.doi.org/10.4103/0377-4929.56121

[10] Li, L.J., Li, Y., Wen, Y.M., Liu, H. and Zhao, H.W. (2008) Clinical Analysis of Salivary Gland Tumor Cases in West China in Past 50 Years. Oral Oncology, 44, 187-192. http://dx.doi.org/10.1016/j.oraloncology.2007.01.016

[11] Jude, U.O. and Olu-Eddo, A.N. (2014) Salivary Gland Tumors, a Twenty-Year Retrospective Study. African Journal of Medical and Health Sciences, 13, 24-29. http://dx.doi.org/10.4103/2384-5589.139439

[12] Eveson, J.W., Auclair, P., Gnepp, D.R. and El-Naggar, A.K. (2005) Tumours of the Salivary Glands: Introduction. In: Barnes, L., Eveson, J.W., Reichat, P., Sidranksky, D., Eds., Pathology and Genetics of Head and Neck Tumours, Lyon, 212.

[13] Yaor, M.A. (2010) The Pattern of Presentation of Salivary Gland Tumors in Africa: A Review of Published Reports. Ear, Nose \& Throat Journal, 89, E17-E21.

[14] Silas, O.A., Echejoh, G.O., Menasseh, A.N., Mandong, B.M. and Otoh, E.C. (2009) Descriptive Pattern of Salivary Gland Tumors in Jos University Teaching Hospital: A 10-Year Retrospective Study. Annals of African Medicine, 8, 199-202.

[15] Otoh, E.C., Johnson, N.W., Olasoji, H., Danfillo, I.S. and Adeleke, O.A. (2005) Salivary Gland Neoplasms in Maiduguri, Northeastern Nigeria. Oral Diseases, 11, 386-391. http://dx.doi.org/10.1111/j.1601-0825.2005.01137.x

[16] Taiwo, O.A., Olusola, A.S. and James, E.T. (2014) Clinico-Pathologic Spectrum of Salivary Gland Tumours and Its Management in a Suburban Tertiary Centre. Advanced Biomedical Research, 5, 124-129.

[17] Lawal, A.O., Adisa, A.O., Kolude, B., Adeyemi, B.F. and Olajide, M.A. (2013) A Review of 413 Salivary Gland Tu- 
mours in the Head and Neck Region. Journal of Clinical and Experimental Dentistry, 5, e218-e222. http://dx.doi.org/10.4317/jced.51143

[18] Kalburge, J.V., Kalburge, V., Latti, B. and Kini, Y. (2014) Salivary Gland Tumors: Clinicopathologic Analysis of 73 Cases. Journal of Cranio-Maxillary Diseases, 3, 111-115. http://dx.doi.org/10.4103/2278-9588.138224

[19] Kolude, B., Lawoyin, J.O. and Akang, E.E. (2001) Salivary Gland Neoplasms: A 21 Year Review of Cases Seen at University College Hospital, Ibadan. African Journal of Medicine and Medical Sciences, 30, 95-98.

[20] Ito, F.A., Ito, K., Vargas, P.A., de Almeida, O.P. and Lopes, M.A. (2005) Salivary Gland Tumors in a Brazilian Population: A Retrospective Study of 496 Cases. International Journal of Oral \& Maxillofacial Surgery, 34, 533-536. http://dx.doi.org/10.1016/j.ijom.2005.02.005

[21] Ladeinde, A.L., Adeyemo, W.L., Ogunlewe, M.O., Ajayi, O.F. and Omitola, O.G. (2007) Salivary Gland Tumours: A 15-Year Review at the Dental Centre Lagos University Teaching Hospital. African Journal of Medicine and Medical Sciences, 36, 299-304.

[22] Chidzonga, M.M., Lopez Perez, V.M. and Portilla-Alvarez, A.L. (1995) Salivary Gland Tumours in Zimbabwe: Report of 282 Cases. International Journal of Oral \& Maxillofacial Surgery, 24, 293-297. http://dx.doi.org/10.1016/S0901-5027(95)80032-8

[23] Oti, A.A., Donkor, P., Obiri-Yeboah, S. and Afriyie-Owusu, S. (2013) Salivary Gland Tumours at Komfo Anokye Teaching Hospital, Ghana. Surgical Science, 4, 135-139.

[24] Ajike, S.O., Adebayo, A.T. and Adekeye, E.O. (2003) Minor Salivary Gland Tumours in Kaduna, Nigeria. The Nigerian Journal of Surgical Research, 5, 100-105. 